\title{
Applying Task-based Language Teaching in Introductory-Level Mandarin Language Classes at The College of The Bahamas
}

\author{
Youhua Zhou \\ Confucius Institute, The College of The Bahamas and \\ Nanjing University of Information Science \& Technology ${ }^{1}$
}

\section{ABSTRACT}

In foreign-language teaching and learning, there exist a number of methodologies and approaches. The ideas and principles of Task-based Language Teaching (TBLT) and learning have proven to be effective in classrooms. The three pedagogic goals of task-based approachescommunication, restructuring and fluency-are also the goals of Mandarin learners. Using examples, this paper explains that Task-based Language Teaching applied in introductory level Mandarin classes at The College of The Bahamas is helpful and that enthusiastic Bahamian learners can improve their Mandarin skills by completing various activities and tasks within the task-based framework. Observations and results obtained through using this strategy have shown that TBLT is effective in classroom Mandarin teaching and learning for Bahamian college students and adult learners, though some issues exist which warrant further discussion.

\section{INTRODUCTION}

In foreign language teaching, successful learning is influenced by appropriate methods of teaching. The 20th century has seen a succession of methodologies and approaches, including the Grammar-translation Method, the Direct Method, the Communicative Approach and so on. These methodologies and approaches have influenced foreign language teaching in various ways. Towards the end of the 20th century, Task-based Language Teaching (TBLT) began to garner keen interest as a way to promote the development of communicative skills. The emphasis on task-based teaching and learning is also reflected in much contemporary research, such as the studies by Long and Crookes (1991), Skehan and Foster (1999), and Johnson (2001).

\section{TBLT and the Task-based Framework}

The meaning of "task" has been defined in various ways. According to Nunan it is "a piece of classroom work which involves learners in comprehending, manipulating, producing or interacting in the target language while their attention is principally focused on meaning rather than form" (1989, p. 10). Skehan lists characteristics of a task as: (a) meaning is primary; there is some

\footnotetext{
${ }^{1}$ Youhua Zhou, Co-Director, Confucius Institute, The College of The Bahamas, P.O. Box N-4912, Nassau, Bahamas. Nanjing University of Information Science \& Technology, 210044, Nanjing, China.

Acknowledgments: The author is grateful to the Managing Editor, Virginia Ballance and the two anonymous reviewers whose comments and advice improved the paper.

E-mail: youhua.zhou@cob.edu.bs

APA reference: Zhou, Y. (2016). Applying task-based language teaching in introductory-level Mandarin language classes at The College of The Bahamas. The International Journal of Bahamian Studies, 22, 34-42. http://dx.doi.org/10. 10.15362/ijbs.v22i0.253
}

(C) Y. Zhou, 2016. Journal compilation (c)The International Journal of Bahamian Studies, 2016 
communication problem to solve; (b) there is some sort of relationship to comparable realworld activities; (c) task completion has some priority; and (d) the assessment of tasks is in terms of outcome (1998, p. 95). Willis gives the meaning of task as "a goal-oriented activity in which learners use language to achieve a real outcome" (1996, p. 53). Ellis says, "A task involves a primary focus on pragmatic meaning. It has a clearly defined, non-linguistic outcome" (2003, pp. 4-5).

It is important to note that there is a clear distinction between tasks and activities that are designed to provide practice of a grammatical structure. Willis and Willis contrast tasks with form-focused activities as follows: "The use of the word 'task' is sometimes extended to include metacommunicative 'tasks' or exercises with a focus on language form, in which learners manipulate language or formulate generalizations about form" (2001, p. 173). For extensive reviews of task characteristics and categories that have been proposed, see Ellis (2003), Nunan (1993, 2004), Robinson (2001, 2007), and Samuda and Bygate (2008).

Task-based language teaching (TBLT) focuses on the use of authentic language to carry out meaningful tasks in the target language. In foreign language classrooms, it is the teacher's responsibility to help students to learn how to communicate using the target language; the teacher therefore needs to design meaning-based activities and tasks for students to complete. Willis asserts, "A taskbased approach is normally realized through a deep-end strategy whereby learners do their best to achieve some kind of resolution to a communicative problem through the deployment of their language resources" (1996, p. 46). As Cook (2010) noted, TBLT "sees second language learning as arising from particular tasks that students do in the classroom" and TBLT is the approach to language teaching "that has attracted most attention in the past decade" (p. 512).

By asking students to complete a series of meaningful tasks, focus is placed on the ability to communicate using the vocabulary and structures taught. In the task-based language class, the activities lead up to the completion of a realistic task and the language taught is determined by what the students would need to know in order to complete it. In an English class in China, tasks assigned to students may include: "Report five things to the class (or to your group) that you did yesterday" so that, in addition to knowing the necessary vocabulary, the students would need to use the past tense, which is quite challenging, as in Chinese, there are no tenses like the past tense. In a Mandarin class taught in the Bahamas, similar tasks would be given to the students.

After practicing expressions used in Mandarin to describe the weather, a task given to students in groups of four might be as follows: "Imagine that you are friends with three Chinese students who live in Beijing, Shanghai and Nanjing and who speak no English. You will call them in turn via Skype from Nassau and ask them what the weather is like there". In advance of class, each student would have to find out what the weather is like in their assigned city in order to be able to answer the questions accurately. While the learners are doing this task using Mandarin to talk with their Chinese friends, they are all improving their communicative ability. When completing many tasks of this nature, the learners will learn how to interact with Mandarin speakers in authentic situations.

Storch explains, "When learners engage with tasks, they bring with them particular dispositions and notions of how the task might be approached" (2002, p. 121). And, when students have completed their tasks in the Chinese classroom, the teachers usually provide feedback that helps students 
understand language forms as well as meanings. According to Batstone, one aspect of the research into TBLT that has proved to be particularly profitable over the past years is the idea that specific aspects of language acquisition are facilitated when learners have opportunities to clarify uncertainties about language form, or when they correct errors in their own or in others' language production by engaging in interaction which leads to the provision of corrective feedback (2012, p. 463).

There are three pedagogic goals for task-based approaches: (a) accuracy of the message communicated, (b) complexity/restructuring and (c) fluency (Skehan, 1996, p. 40). In order to achieve these three goals in classroom language teaching, many tasks would usually be done within a framework developed over a period of time and proven to be effective
(Willis, 1996, p. 52). The complete framework aims to create the essential conditions for language learning.

In an Introductory Level II Mandarin class, tasks such as the following can be designed for the students: "Imagine that you are planning to spend two weeks visiting China and that you need to decide which two out of the following three cities you will visit: Beijing, Shanghai, or Nanjing. Work in a group of three. Each person in the group gets information about a different city. Use textbooks or online sources to find out interesting information to fill out a table. Make notes using key words and phrases and tell this information to your group using Mandarin. Then ask one another questions, so that each person can make a decision regarding which two cities he or she will visit".

\begin{tabular}{|l|l|l|l|}
\hline Framework & Information on three cities \\
\hline Activities/Tasks & \multicolumn{1}{|c|}{ Beijing } & \multicolumn{1}{|c|}{ Shanghai } \\
\hline Pre-class work & $\begin{array}{l}\text { Checking words: } \\
\text { 长城 Chángchéng (the Great } \\
\text { Wall; 故宫 Gùgōng (Palace } \\
\text { Museum), etc. }\end{array}$ & $\begin{array}{l}\text { Looking for information: } \\
\text { 高楼林立 gāolóu línlì } \\
\text { (skyscrapers) } \\
\text { 繁华 fánhuá (prosperous), etc. }\end{array}$ & $\begin{array}{l}\text { Finding key words: } \\
\text { 历史悠久 lìshǐyōujiǔ (long history), } \\
\text { capital), etc. }\end{array}$ \\
\hline In-class work & $\begin{array}{l}\text { Group work, exchanging information about different cities, using the sentences as “我知道...” (I know ...) to } \\
\text { tell your group the information }\end{array}$ \\
\hline Post-class work & $\begin{array}{l}\text { State which two cities you have decided to visit and why, identifying and writing characters such as 长城, } \\
\text { 繁华, 悠久 ; talking with your friends using 我非常喜欢... (I like ... very much.) etc. }\end{array}$ \\
\hline Follow-up work & $\begin{array}{l}\text { Viewing cultural videos about the three cities in China and exchanging cultural knowledge learned from the } \\
\text { video... }\end{array}$ \\
\hline
\end{tabular}

By completing this task, the learners will develop their ability to communicate in Mandarin and to express information on three major Chinese cities. The learners will understand the function of “我知道 ..." “我非常喜欢...” etc. and would be able to use them to speak with native Chinese when they visit China one day.

The results obtained by students at The
College of The Bahamas after doing tasks in the Mandarin classes have proved that the task-based framework is useful in promoting the development of communicative skills. The goals of communicative effectiveness, restructuring and fluency in Mandarin can be achieved by completing the tasks.

\section{TBLT in Mandarin Classes at COB}

Based on the research done on TBLT in foreign language teaching and the decision 
was taken to implement TBLT in the Introductory Level Mandarin classes at The College of The Bahamas (COB).

The textbooks chosen for Mandarin learners at COB are New Practical Chinese Reader I \& II (Liu, 2010) and Standard Course HSK I \& II (Jiang, 2014); these books include an audio CD. A workbook of exercises that aim to help learners strengthen their learning supports each textbook. The textbooks suggest adopting the communicative approach and task-based language teaching; they are student-centered, focusing on the development of students' integrated language skills. Furthermore, additional materials help learners to improve their listening, speaking, reading and handwriting skills.

\section{Learning Pinyin and the Tones of Mandarin}

There is a saying that Mandarin is one of the most difficult languages to learn and that the pronunciation of the four tones plus the weak tone is difficult for learners, especially beginners, to grasp. This is true to some extent; however, any language is difficult to learn for the beginner, including English, even though it is the most widely spoken language in the world. Any language including Mandarin can be learned well through exposure and practice. In spite of the perceived difficulty, according to the statistics collected by the Confucius Institute Headquarters, at the end of 2014 there were more than 100 million learners worldwide studying Chinese Mandarin as a foreign language (http://news.xinhuanet.com/world /2014-08/28/c_1112271530.htm ).

For COB Mandarin learners at the introductory level, both for the college credit course and for the adult learners, three hours weekly in class were scheduled for them to learn and practice Pinyin, or Hanyu Pinyin, which is a system for writing Mandarin using the Roman alphabet in order to assist students who are learning Mandarin as a foreign language. After class, learners are required to review and practice Pinyin and the four tones by listening to the $\mathrm{CD}$ or through online resources. Except for a few initials like $z h, c h$, $r$, or finals like $\ddot{u} e$ and eng that are somewhat difficult for most beginners to pronounce, the learners can pronounce almost all the other initials and finals very well.

However, the four tones seem to be more difficult. Examples are $m \bar{a}, m a ́, m a ̆$, and $m a ̀$, which are pronounced differently and carry different meanings in Chinese. Most of the learners can pronounce the first tone $(m \bar{a})$ and the third tone ( $m a ̆)$ quite well, but have greater difficulty with the second tone (má), and the fourth tone (mà). However, with the application of TBLT in the Introductory Level Mandarin class at COB, Bahamian learners have been able to significantly develop their Mandarin skills.

\section{Pre-class Activities for the Learners}

Each chapter in the above-mentioned textbooks has a theme and gradually leads up to the point where the students are asked to accomplish a realistic communicative task using Mandarin, a task which they could reasonably be faced with in China or when speaking to Chinese persons.

Before beginning a new chapter, students are required to do some pre-class activities in order to be well prepared for classroom learning and practice. For example, Chapter 12 in Standard Course HSK I is based on the topic, "Míngtiān tiānqì zěnmeyàng?" ("What will the weather be like tomorrow?"). Before coming to class, students do pre-class activities, such as matching the pictures with the words/phrases and these activities help the students learn the vocabulary and expressions related to the weather. Students are also asked to listen to the $\mathrm{CD}$ for the pronunciation and, specifically, the tones of words like lèng 冷 
(cold), rè 热 (hot) as well as listening to the dialogues in this chapter. These activities stimulate the students' interest and they particularly enjoy the Chinese pictograph 雨 $y \breve{u}$ (rain, which itself looks like rain).

\section{Classroom Activities That Prepare Students to} Accomplish a Task

Students do a series of class activities designed for each chapter. Before attempting new material, students usually write a fiveminute dictation in Pinyin of the words and key sentences learned in the previous chapter. After writing the dictation in their notebooks, two students volunteer to write the words and sentences on the whiteboard. Then, the instructor asks the students, including the two who have just written on the board, to check and make any necessary corrections. This activity engages the interest of the entire class, as students know that they will not only check the others' dictation but also check their own. The instructor explains relevant points while doing this work together with the whole class. Thus, the students' knowledge of Mandarin is consolidated. As any learner tends to make mistakes when learning a new language, the instructor is always very encouraging, so that students would not be embarrassed in front of their classmates. In practice, almost all the introductory level students love to come to the board and write the dictation, as they know that this work helps them to learn and grasp the key language points, especially the difficult four tones.

After the dictation, the class focuses on the new content in the chapter, learning new words and phrases, understanding key structures and reading situational conversations. Following this, some reading activities are done and the students practise and consolidate their learning. Students work in pairs or groups, reading the situational conversations, with the instructor walking around ready to answer questions about the pronunciation, the tones or the meanings of certain sentences. A role-play activity follows this. Usually two to four students perform a dialogue in front of the class and there is generally a lively atmosphere. The whole class usually gives each pair or group warm applause when they finish, which the participants find very encouraging.

For example, in the Introductory Chinese 103 class based on Chapter 13, several groups were eager to come to the front to perform a situational conversation, describing what is happening in the kitchen: Tã zài xué zuò Zhōngguó cài ne 他在学做中国菜呢。(He is learning to cook Chinese food). By doing the role-play activity, most students can grasp the key structure zài zuò shénme 在做什么? and zài...ne 在...呢, indicating present continuous tense in English and they also improve their pronunciation, particularly the neutral tone. It was significant that, as a result of performing the conversation, many students were able to differentiate between the second and fourth tones coming together, both of which are challenging for Mandarin learners. Each time some students had difficulty in pronouncing the second tone " / " or the fourth tone " $\backslash$ ", the correct pronunciation would be explained again to them, as, with the second tone, the voice rises, and, for the fourth tone, the voice falls. Again, the pronunciation of the tones would be modelled to students with some body language, to promote effective learning. Most Bahamian learners realize that when they meet the second tone, it is helpful to pronounce it with their heads moving upward, and pronounce the fourth tone while moving their heads in a clear downward motion.

In each chapter in the books Standard Course $H S K I \& I I$, there is an activity in which the learners trace and learn how to write Chinese characters, many of which are pictographic 
like 日 rì (sun), 月 yuè (moon) and 山 shān (mountain) or ideographs like 明 míng (bright), 睡 shuì (sleep), and 钉 dīng (nail). Most students show great interest in tracing and writing them, and many write the Chinese characters well, even at an early stage of learning Mandarin.

\section{Tasks Assigned after Class}

A workbook with various exercises supports each textbook, Standard Course HSK I \& II, and helps learners to strengthen their skills. Students complete listening, reading, pronunciation and writing exercises. They write Chinese characters in specially designed boxes. These exercises focus closely on the vocabulary and key language structures in the text. By doing the exercises in the workbook, the students' learning of the language points is consolidated; each workbook is graded and. feedback is provided. They also do additional activities, such as pair work, with students telling each other what they like doing in their spare time or reciting the conversations in the text in order to improve their pronunciation and communicative skills. Ultimately, the various exercises together equip the students to carry out a realistic communicative task in Mandarin that they might need to accomplish either when they visit China or when speaking to a Chinese friend on Skype. Generally, the students respond in a positive manner to the activities and to the challenges of the task and improve their ability to speak the language.

Bahamian learners, both college students and adult learners from varying professional backgrounds in the Bahamas, have shown great interest in learning Mandarin since the establishment of the Confucius Institute at $\mathrm{COB}$ in 2012. As a result, hundreds of COB students and Mandarin learners have taken part in cultural activities each year. Furthermore, since 2013, annually at least one group has visited China and the students have had wonderful experiences there. In the summer of 2015, two groups, one consisting of eight Bahamian educators and the other of 14 Bahamian college students traveled to China. The "Experiencing Chinese Culture Programme" not only helps Mandarin learners improve their conversational skills and discover more about China, but also helps to deepen the friendship between Chinese and Bahamian people.

When learning Mandarin, a new world opens up for the students, who discover the rich Chinese culture, which has a history of more than 5000 years. Thus, each semester Bahamian students are exposed to aspects of Chinese culture, such as festivals, natural wonders, traditions such as the celebration of the Chinese Lunar New Year, Chinese movies, Chinese songs, Chinese calligraphy, and Taiji. Such exposure broadens their view and understanding about China and the Chinese way of life, thereby preparing them for a future visit.

\section{Effect of the TBLT on Bahamian Learners}

Since 2013, TBLT has been implemented in the Mandarin classes for both Bahamian college students and other learners. In the classroom setting, the learning activities are applied according to the four phases. The textbooks provide realistic communicative tasks, which the students must accomplish. (For the sake of appropriateness and effectiveness, some adaptations have been made to the textbook tasks and some supplementary materials have been added).

Almost every student at $\mathrm{COB}$ was taking a Mandarin course for the first time when he or she entered the Mandarin class. All showed their interest in learning Mandarin and in finding out more about Chinese culture. Because a wide array of materials that promote learning Mandarin is easily 
accessible online, after one semester of classes that were organized around the taskbased approach, many students become effective independent learners, supplementing classroom instruction with online materials. These students have become aware of the fact that the development of communicative ability in listening, speaking, reading and writing mainly relies on their own engagement and initiative. In fact, quite a few students have Chinese friends in China and they talk with them about education, weather and daily life through Skype or Weichat in Mandarin.

At the end of each semester in the credit class, usually one-third of the students achieve an A grade. Most credit class students can get $\mathrm{B}+$ and above because of having accomplished a series of tasks, using their initiative and many opportunities to practice speaking the language in Mandarin classes. Close to the end of each semester, the students are interviewed in order to assess the effectiveness of the task-based approach. Most of the students think that they have benefited a lot and improved their Mandarin significantly as a result of accomplishing these tasks. One of the issues that warrant further investigation is how to plan and control the time allotted for doing each task.

So far, 81 Bahamian students have successfully completed the Standard Course HSK I \& II and HSKK Junior programme. Another achievement is that since 2013, of the students in the Mandarin classes at COB, 23 have successfully acquired Confucius Institute scholarships to take immersion classes in China and four have been granted Chinese government scholarships to pursue their studies in their discipline at a Chinese university. Thus, the conclusion may be drawn that TBLT has been effective in developing the students' learning and competence in Mandarin.

\section{Discussion}

Although the results of the application have indicated that TBLT is effective in improving Bahamian students' level of Mandarin, readers of this paper are expected to interpret them with caution. First, the number of the learners is rather limited. It remains to be tested whether this approach would be as effective if used on a larger scale. Second, some difficulty in designing appropriate and realistic activities and tasks has been experienced, and some of the activities and handouts were found to be unsatisfactory. Third, further work is needed on the time limits for implementing the activities and tasks in classes. It was noted that sometimes the activities and tasks could only be completed if the students had prepared adequately before the class. Also, as found elsewhere, challenges in completing tasks include the fact that "... beginners usually have rather low linguistic knowledge and learning originating in the nature of the Chinese language itself, and the effectiveness of cooperation and interaction in small groups is sometimes influenced by group cohesion and member familiarity" (Ruan, Duan, \& Du, 2015, p. 51).

Finally, in Mandarin teaching and learning, it is necessary that both instructors and learners understand the principles behind TBLT. When the learners are doing the activities and tasks within the task-based framework with clear instructions, they are developing their ability to communicate in Mandarin, their cultural understanding and their confidence and ability to interact with native speakers. 


\section{REFERENCES}

Batstone, R. (2012) Language form, taskbased language teaching, and the classroom context. ELT Journal, 66(4), 459-467. http://dx.doi.org/10.1093/elt/ccs058

Cook, V. (2010). Linguistic relativity and language teaching. In V. Cook \& A. Bassetti (Eds.), Language and bilingual cognition (pp. 509-518). New York, NY: Psychology Press.

Ellis, R. (2003). Task-based language learning and teaching. Oxford, England: Oxford University Press.

Foster, P., \& Skehan, P. (1999). The influence of source of planning and focus of planning on task-based performance. Language Teaching Research, 3(3), 215247.

http://dx.doi.org/10.1177/13621688990030 0303

Jiang, L. (2014). Standard course HSK I \& II. Beijing, China: Beijing Language and Cultural University Press.

Johnson, K. (2001). An introduction to foreign language teaching and learning. London, England: Longman.

Liu, X. (2010). New practical Chinese reader $I \& I I$. (2nd Ed.). Beijing, China: Beijing Language and Cultural University Press.

Long, M., \& Crookes, G. (1991). Three approaches to task-based syllabus design. TESOL Quarterly, 26, 27-55. http://dx.doi.org/10.2307/3587368

Long, M., \& Crookes, G. (1993). Units of analysis in syllabus design: the case for task. In G. Crookes \& S. Gass (Eds.), Tasks in pedagogic context: Integrating theory and practice (pp. 9-54). Clevedon, England: Multilingual Matters.

Nunan, D. (1989). Designing tasks for the communicative classroom. Cambridge, England: Cambridge University Press.

Nunan, D. (1993). Task-based syllabus design: Selecting, grading and sequencing tasks. In G. Crookes \& S. Gass (Eds.), Tasks in a pedagogical context: Integrating theory and practice (pp. 5568). Clevedon, England: Multilingual Matters.

Nunan, D. (2004). Task-based language teaching. Cambridge, England: Cambridge University Press.

Robinson, P. (2001). Task complexity, cognitive resources, and syllabus design: A triadic framework for investigating task influences on SLA. In P. Robinson (Ed.), Cognition and second language instruction (pp. 287-318). Cambridge, England: Cambridge University Press.

Robinson, P. (2007). Criteria for classifying and sequencing pedagogic tasks. In M. P. Garcia Mayo (Ed.), Investigating tasks in formal language learning (pp. 7-27). Clevedon, England: Multilingual Matters.

Ruan, Y., Duan, X., \& Du, X. Y. (2015). Using tasks to enhance beginners' orientations for learning Chinese as a foreign language. International Journal of Research Studies in Language Learning, 4(4), 41-55. http://dx.doi.org/10.5861/ijrsll.2015.1044

Samuda, V., \& Bygate, M. (2008). Tasks in second language learning. London, England: Palgrave Macmillan.

Skehan, P. (1996). A framework for the implementation of task-based instruction. Applied Linguistics, 17(1), 38-62. http://dx.doi.org/10.1093/applin/17.1.38

Skehan, P., \& Foster, P. (1999).The influence of task structure and processing conditions on narrative retellings. Language 
Learning, 49, 93-120.

http://dx.doi.org/10.1111/1467-9922.00071

Storch, N. (2002). Patterns of interaction in ESL pair work. Language Learning, 52, 119-158. http://dx.doi.org/10.1111/14679922.00179

Willis, J. (1996). A flexible framework for task-based learning. In D. Willis \& J. Willis (Eds.), Challenge and change in language teaching (pp. 52-62). Oxford, England: Heinemann.

Willis, D., \& Willis, J. (2001). Task based language learning. In R. Carter and D. Nunan (Eds.), The Cambridge guide to teaching English to speakers of other languages (pp. 173-179). Cambridge, England: Cambridge University Press. 